\title{
Biological and biochemical characterization of 4-META/ MMA-TBB resin
}

\author{
Kaori Nakagawa ${ }^{1}$, Takayuki Ikeda ${ }^{1}$, Makiko Saita ${ }^{1}$, Makoto Hirota $^{1}$, Masako Tabuchi $^{1}$, Wonhee \\ Park $^{1}$, Masaichi Chang-Il Lee ${ }^{2}$, and Takahiro Ogawa ${ }^{1 *}$ \\ ${ }^{1}$ Weintraub Center for Reconstructive Biotechnology, UCLA School of Dentistry, 10833 Le Conte Avenue, Los Angeles, California, 90095-1668, USA \\ ${ }^{2}$ Department of Clinical Care Medicine, Kanagawa Dental College, Yokosuka, Japan
}

Received: September 11, 2015; Accepted: October 15, 2015; Published: November 20, 2015

*Corresponding author: Takahiro Ogawa, The Weintraub Center for Reconstructive Biotechnology, UCLA School of Dentistry, Los Angeles, CA, 10833,TEL:+310-825-0727; FAX:+310- 825-6345;E-mail: togawa@dentistry.ucla.edu

\begin{abstract}
4-META/MMA-TBB resin has clinically favorable mechanical and bonding properties and undergoes unique, moisture-insensitive polymerization. To explore the potential usefulness of 4-META/ MMA-TBB resin as a pulp capping material, this study examined its biological and biochemical properties. Rat dental pulp cells were cultured on 4-META/MMA-TBB resin, resin-modified glassionomer (RMGI) cement, and a calcium hydroxide-based pulp capping material. The percentage of viable cells was considerably higher on 4-META/MMA-TBB resin than on RMGI and calcium hydroxide $24 \mathrm{~h}$ after seeding. The number of attached cells and their proliferative and alkaline phosphatase activities were significantly higher on 4-META/ MMA-TBB resin during the later stages of culture. Fourier transform infrared (FT-IR) and electron spin resonance (ESR) spectroscopic analyses showed that polymerization of the 4-META/MMA-TBB resin was faster and more complete than the RMGI and calcium hydroxide, with minimal production of free radicals. These results collectively and consistently demonstrated that 4-META/MMA-TBB resin possesses a higher level of biological and biochemical compatibility with dental pulp cells than RMGI cement and calcium hydroxide tested. Given the well-established mechanical advantages of 4-META/MMA-TBB resin, the current in vitro results serve as a basis to further explore this material as a pulp capping material and warrant in vivo studies.
\end{abstract}

Keyword: cytotoxicity; pulp capping; resin-modified glassionomer; calcium hydroxide; free radical

\section{Introduction}

When the dental pulp chamber is exposed, it later needs to be plugged and sealed to prevent biological and chemical contamination; this is known as dental pulp capping. Calcium hydroxide-based materials are commonly used as a capping material and effectively maintain pulp vitality and function. When the exposed pulp tissue is covered with calcium hydroxide, a layer of dentin-like mineralized tissue, called the dentin bridge, forms at the interface [1-7]. This dentin-like structure differs from innate tubular dentin and the exact mechanism of how this layer forms is unknown [1, 4, 8-15]. It is thought that the dentine bridge formation is a reaction to chemical stimuli, rather than a regenerative dentinogenic response $[8,9]$; specifically, the strong alkaline property of calcium hydroxide causes chemical trauma that leads to local necrosis and an inflammatory reaction in the pulp tissue $[16,17]$. Under necrotic conditions, dental pulp cells migrate and differentiate into odontoblast-like cells [12], resulting in the formation of a mineralized layer $[5,9]$.

However, despite a pulp capping success rate of $80 \%$ or higher with traditional materials, failures still occur, with acute inflammation and pain, and chronic pulpal necrosis, and infection; this may progress to periapical lesions [4, 7]. Incomplete and unpredictable formation of the dentin bridge, a weak and unstable mechanical strength of capping, and limited ability of dentin bonding, and, importantly, biological compatibility of calcium hydroxide materials, may be targets for future improvement.

Currently-used various dental restorative resin materials have sufficient mechanical and bonding properties for their intended purposes. However, critical disadvantages of these materials, including a lack of cell and tissue compatibility and adverse sensitivity to moisture which substantially interferes with polymerization, preclude their use as a direct pulp capping material. 4-META/MMA-TBB is used in resinous luting and bonding materials, and consists of methyl methacrylate (MMA), poly-MMA (PMMA), and 4-methacryloyloxylethyl trimellitate anhydride (4-META), and tri-n-butyl borane (TBB) as the polymerization initiator[18-20]. The molecular structure of 4-META was originally designed and synthesized using a proprietary protocol. 4-META/MMA-TBB resin bonds strongly to dentin and metal and polymerizes more rapidly than PMMAbased materials[18, 21-25]; their clinical applications therefore range from cavity restoration to splinting mobile teeth and treating fractured teeth[18]. Due to improved biocompatibility and mechanism of polymerization that is not compromised by moisture (not even with blood), 4-META/MMA-TBB has been successfully used for mucosal healing and bone bonding in experimental animal models [26-29] .

In this study, we tested the hypothesis that 4-META/MMATBB resin is biocompatible and can be used as a direct pulp 

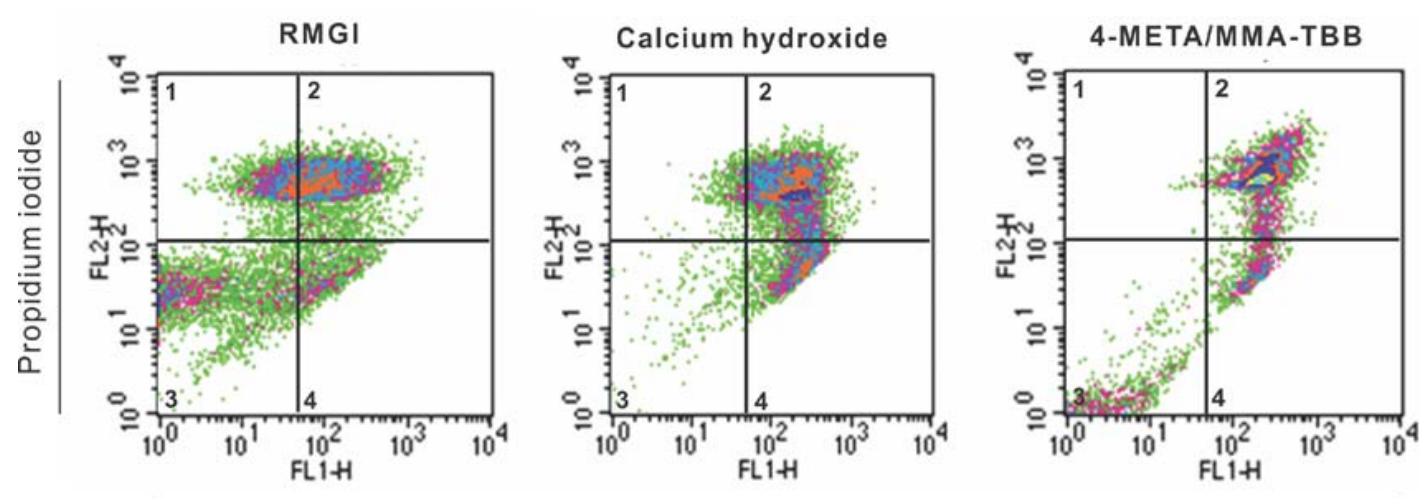

Annexin-V
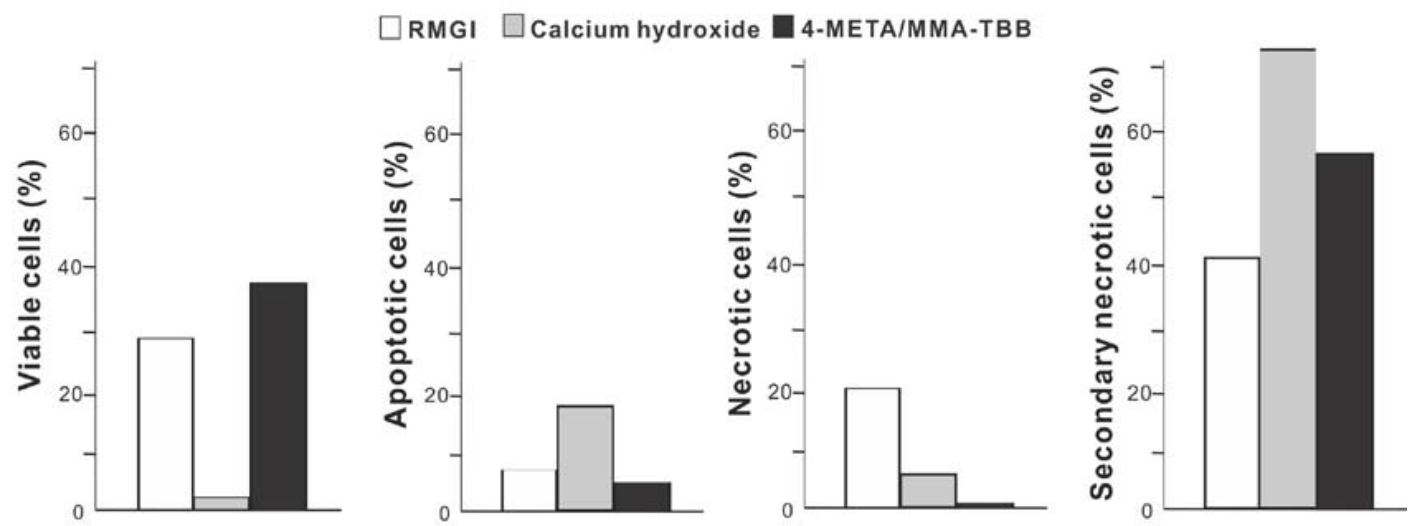

Figure 1: Flowcytomety-based viability/death analysis of dental pulp cells on various dental restorative materials. Cells 24 hours after seeding onto these materials were analyzed. Flow cytometric images (top) and percentages of viable cells (quadrant 3 on the top images), apoptotic cells (quadrant 4), necrotic cells (quadrant 1), and secondary necrotic cells (quadrant 2).

capping material. The specific working hypotheses were that: 1) 4-META/MMA-TBB resin is less cytotoxic than calcium hydroxide; 2) the dental pulp cells show the expected functional phenotype when cultured directly on 4-META/MMA-TBB resin; and 3 ) the reduced cytotoxicity of 4-META/MMA-TBB resin is a consequence of favorable material biochemistry compared to other resin-containing restorative materials. These cell-based studies lay the foundation for future in vivo studies and the longterm goal of developing a pulp capping material that is capable of regenerating dentin in addition to the well-established ability of this material for tissue sealing and maintaining mechanical stability. The objective of this study was to examine the viability and function of dental pulp cells cultured on a 4-META/MMA-TBB resin, a calcium hydroxide-based material, and resin-modified glass ionomer (RMGI) cement, and investigate the polymerization behavior of these materials.

\section{Materials and methods}

\section{Substrate preparation}

Substrate materials were prepared according to the manufacturer's instructions using three different types of commercial products, RMGI (Fuji II LC, GC America, Alsip, IL), calcium hydroxide-based pulp-capping material (Dycal, Dentsply, Milford DE), 4-META/MMA-TBB resin (Super-bond C\&B, Sun Medical, Moriyama, Japan), and spread evenly in a well of 12 well cell culture grade polystyrene dishes with a thickness of 0.4 $\mathrm{mm}$. Because the RMGI used in this study was based on the dualcure mechanism of chemical- and light-cure, it was irradiated with visible light (450-490 nm) for $25 \mathrm{~s}$ using a $1200 \mathrm{mw} / \mathrm{cm}^{2}$ light emitting diode instrument (Blue Life LED-320 Cordless, Microtech, Tokyo, Japan). Cells were seeded on the substrates immediately after preparation.

\section{Dental pulp cell culture}

Dental pulp cells were isolated from the maxillary incisors of 8-week-old male Sprague-Dawley rats following an established protocol [30-33]. Cells were placed in alpha-modified Eagle's medium supplemented with $15 \%$ fetal bovine serum, $50 \mu \mathrm{g} /$ $\mathrm{ml}$ ascorbic acid, $10^{-8} \mathrm{M}$ dexamethasone, and $10 \mathrm{mM} \mathrm{Na}-\beta$ glycerophosphate, and an antibiotic-antimycotic solution containing 10,000 units/ml penicillin G sodium, $10,000 \mathrm{mg} / \mathrm{ml}$ streptomycin sulfate and $25 \mathrm{mg} / \mathrm{ml}$ amphotericin B. Cells were incubated in a humidified atmosphere of $95 \%$ air and $5 \% \mathrm{CO}_{2}$ at $37^{\circ} \mathrm{C}$. At $80 \%$ confluency, the cells were detached using $0.25 \%$ 


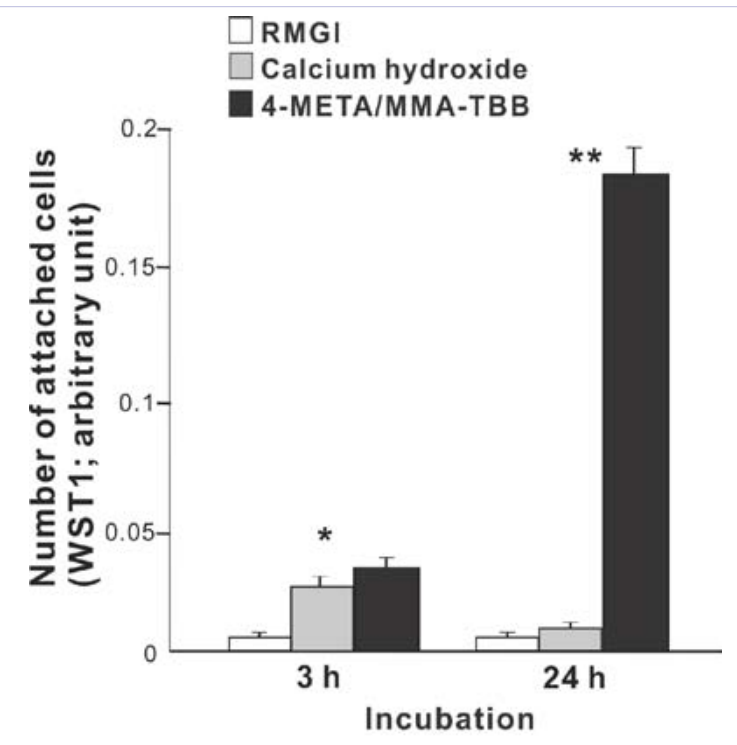

Figure 2: Initial-stage attachment of dental pulp cells to various dental restorative materials. The number of attached cells after incubation for 3 and $24 \mathrm{~h}$, as evaluated by WST- 1 colorimetry. Data are mean \pm SD (n $=3) .{ }^{*} p<0.05,{ }^{* *} p<0.01$, indicating a statistically significant difference among three different materials.
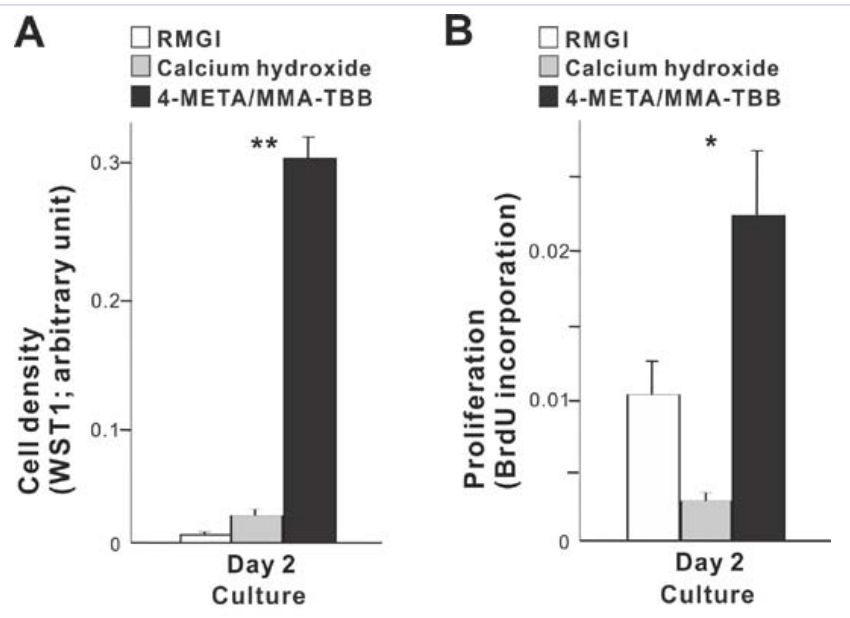

Figure 3: Proliferative activity of dental pulp cells on various dental restorative materials. (A) Cell density at day 2 of culture, as evaluated by WST-1 colorimetry. (B) BrdU incorporation into DNA evaluated at day 2 of culture. Data are mean \pm SD $(n=3) .{ }^{*} p<0.05,{ }^{* *} p<0.01$, indicating a statistically significant difference among three different materials.

trypsin-1mM EDTA-4Na and seeded directly onto the prepared substrates at a density of $3 \times 10^{4}$ cells $/ \mathrm{cm}^{2}$. The culture medium was renewed every 3 days.

\section{Cell viability assay}

To examine the degree of cytotoxicity of the materials, the viability of cultured dental pulp cells was evaluated using a flowcytometry-based assay. The flow cytometric detection of annexin $\mathrm{V}$ binding and propidium iodide (PI) staining (Annexin
V-FITC Kit, BD Bioscience, San Jose, CA, USA) was performed on the cells incubated for $24 \mathrm{~h}$ on the substrates. This method is based on the ability of annexin $\mathrm{V}$ to bind phosphatidylserine (PS) and that of PI to intercalate DNA. The intensity of PI staining (y-axis) was plotted against FITC intensity (x-axis). Viable cells were observed in the lower left quadrant (annexin $\mathrm{V}$ negative/ PI negative), apoptotic cells in the lower right quadrant (annexin $\mathrm{V}$ positive/PI negative), necrotic cells in the upper left quadrant (annexin $\mathrm{V}$ negative/PI positive), and late necrotic cells in the upper right quadrant (annexin $\mathrm{V}$ positive/PI positive).

\section{Cell attachment, density, and proliferation assays}

Initial cell attachment was evaluated by measuring the number of cells attached to the substrates after 3 and $24 \mathrm{~h}$ of incubation. Propagated cells were also quantified as cell density at day 2 of culture. Quantifications were performed through colorimetry using a tetrazolium salt (WST-1) (Roche Applied Science, Mannheim, Germany). A culture well was incubated at $37^{\circ} \mathrm{C}$ for $4 \mathrm{~h}$ with the WST- 1 reagent $(100 \mu \mathrm{l})$ and the amount of formazan produced was measured using an ELISA reader at $420 \mathrm{~nm}$ (Synergy HT, BioTek Instruments, Winooski, VT). The proliferative activity of cells was measured by BrdU incorporation during DNA synthesis. At day 2 of culture, a 100 mM BrdU solution (100 $\mu$ l) (Roche Applied Science) was added to the culture wells and incubated for $10 \mathrm{~h}$. After trypsinizing cells and denaturing DNA, the cultures were incubated with anti-BrdU antibody conjugated with peroxidase for $90 \mathrm{~min}$ and exposed to tetramethylbenzidine for color development. Absorbance was measured using an ELISA reader at $370 \mathrm{~nm}$.

\section{Alkaline phosphatase (ALP) activity}

The alkaline phosphatase activity (ALP) of dental pulp cells was examined at day 7 using image-based and colorimetry-based assays. For the image analysis, cultured cells were washed twice with Hanks' solution, and incubated with $120 \mathrm{mM}$ Tris buffer (pH 8.4) containing $0.9 \mathrm{mM}$ naphthol AS-MX phosphate and 1.8 $\mathrm{mM}$ fast red TR for $30 \mathrm{~min}$ at $37^{\circ} \mathrm{C}$. The ALP-positive area on the stained images was calculated as [(stained area / total dish area)
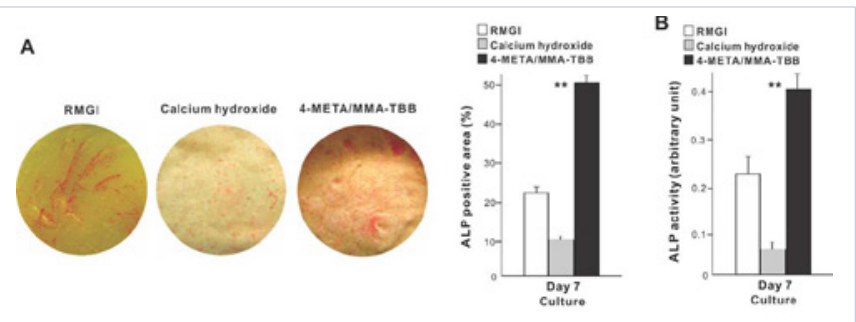

Figure 4: Alkaline phosphatase (ALP) activity in dental pulp cells on various dental restorative materials. (A) Alkaline phosphatase (ALP) activity evaluated by image-based densitometry. Left panels show images of ALP staining of dental pulp cells cultured for 7 days. The ALP-positive area as a percentage of culture area was measured with a digital image analyzer and drawn in histograms. (B) ALP activity evaluated by colorimetry is also presented. Data are mean $\pm S D(n=3) .{ }^{* *} p<0.01$, indicating a statistically significant difference among three different materials. 


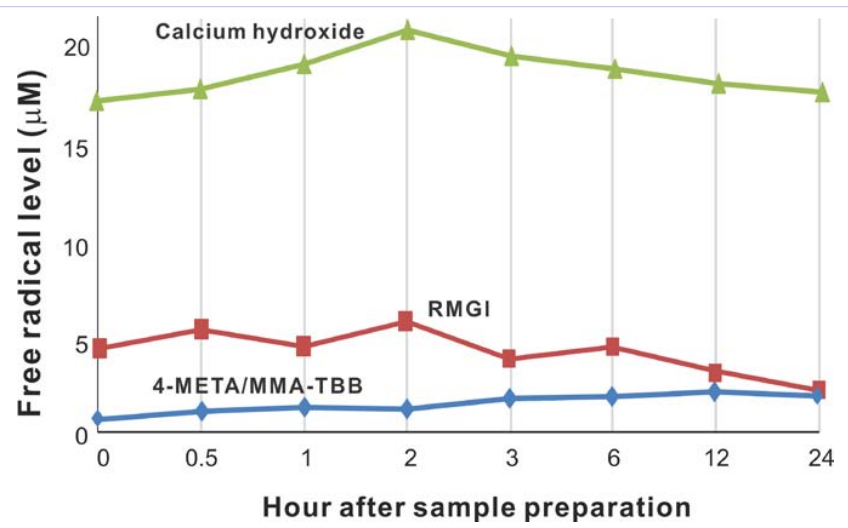

Figure 5: Free radical generation in RMGI cement, calcium hydroxide, and 4-META/MMA-TBB resin. The level of free radicals evaluated by an electron spin resonance spectroscopy (ESR) was plotted from immediately after the sample preparation up to $24 \mathrm{~h}$. Data are mean value $(\mathrm{n}=3)$.

x 100)](\%) using an image analyzer (ImageJ, NIH, Bethesda, ML). For colorimetry, cells were rinsed with $\mathrm{ddH}_{2} \mathrm{O}$ and incubated at $37^{\circ} \mathrm{C}$ for $15 \mathrm{~min}$ in the presence of p-nitrophenylphosphate $(250$ $\mu l)$ (LabAssay ATP, Wako Pure Chemicals, Richmond, VA). ALP activity was evaluated as the amount of nitrophenol released by the enzymatic reaction and measured using an ELISA reader at $405 \mathrm{~nm}$.

\section{FT-IR spectroscopic evaluation for degree of polymerization}

The degree of polymerization was evaluated for RMGI and 4-META/MMA-TBB resin using FT-IR (Spectrum100, PerkinElmer, Shelton, CT) based on the increasing number of repeat units in the polymer chain during polymerization. The ratio of $1720 \mathrm{~cm}^{-1}(\mathrm{C}=0)$ absorbance and $1640 \mathrm{~cm}^{-1}(\mathrm{C}=\mathrm{C})$ was measured at the commencement of power/liquid mixing and 30 min after the mixing, and the degree of polymerization was calculated as the reduction rate of $1640 \mathrm{~cm}^{-1}(\mathrm{C}=\mathrm{C})$ absorbance.

\section{Electron spin resonance spectroscopy (ESR) for} polymerization free radicals

Generation of free radicals within the polymerizing/setting materials was assessed by ESR, which has been validated and developed for the various biomedical applications[34-36]. Specimens of RMGI, calcium hydroxide, and 4-META/MMA-TBB resin were examined using a JES-RE 3X, X-band spectrometer (JEOL,Tokyo, Japan) connected to a WIN-RAD ESR Analyzer (Radical Research, Tokyo, Japan) at the following settings: modulation amplitude, $0.063 \mathrm{mT}$; sweep width, $5 \mathrm{mT}$; sweep time, $1 \mathrm{~min}$; time constant, $0.03 \mathrm{sec}$; microwave power, $8 \mathrm{~mW}$; and magnetic field, $335.5 \mathrm{mT}$. The component signals in the spectra were identified and quantified as reported previously [34]. The level of free radical production was measured at several time points up to $24 \mathrm{~h}$ after specimen preparation.

\section{Statistical analysis}

Three samples were analyzed for cell culture and ESR studies $(\mathrm{n}=3$ ). Flowcytometric analysis was performed 3-5 times, and a representative data set was presented after confirming their consistency. ANOVA was used to assess differences among different substrate materials. When needed, further post-hoc Bonferroni analysis was performed for multiple comparison testings and $\mathrm{p}<0.05$ was considered statistically significant.

\section{Results}

\section{Cell viability on 4-META/MMA-TBB resin}

Flowcytometric analysis revealed that dental pulp cell viability was highest on 4-META/MMA-TBB resin (36.4\%) and lowest on calcium hydroxide (2.5\%) 24 hours after seeding (Fig. 1). The percentage of viable cells was $29.1 \%$ on RMGI. The percentages of apoptotic cells and necrotic cells, which were remarkably lower on 4-META/MMA-TBB resin than on RMGI and calcium hydroxide, accounted for the improved cell viability on 4-META/MMA-TBB resin.

\section{Increased cell attachment to 4-META/MMA-TBB resin}

The number of attached dental pulp cells was significant different among the cultures after $3 \mathrm{~h}$ of incubation and was significantly higher on calcium hydroxide and 4-META/MMATBB resin than on RMGI (Fig. 2). The high number of attached cells persisted on 4-META/MMA-TBB resin after $24 \mathrm{~h}$ of incubation. Notably, the number of attached cells was significantly reduced between 3 and $24 \mathrm{~h}$ of incubation on calcium hydroxide. The number of attached cells on RMGI did not significantly increase during this time.

\section{Increased cell proliferation on 4-META/MMA-TBB resin}

Based on the increased cell attachment during the first $24 \mathrm{~h}$ on 4-META/MMA-TBB resin, we next determined whether the number of cells and proliferative activity increased accordingly over the longer periods of culture. The cell density on 4-META/ MMA-TBB resin was approximately 15 times greater than that on calcium hydroxide, and 60 times greater than that on RMGI, after two days of culture (Fig. 3A). The proliferative activity measured by BrdU incorporation into DNA was significantly higher on 4-META/MMA-TBB resin than on the other two substrates (Fig. 3B). The proliferative activity on RMGI surpassed that on calcium hydroxide.

\section{Increased expression of functional phenotype on 4-META/MMA-TBB resin}

The ALP-positive area measured was highest on 4-META/ MMA-TBB resin at day 7, followed by the ones on RMGI and calcium hydroxide. (Fig. 4A). Likewise, the colorimetry-detected ALP was greatest in cells cultured on 4-META/MMA-TBB resin, followed by RMGI and then calcium hydroxide. ALP activity on 4-META/MMA-TBB resin was approximately eight times greater than on calcium hydroxide.

Favorable polymerization behavior of 4-META/MMATBB resin

FT-IR spectroscopic analysis showed that the degree of 
polymerization was $82 \%$ for 4-META/MMA-TBB resin and only $40 \%$ for RMGI 30 min after sample preparation. ESR analyses showed that free radical production was very low from 4-META/ MMA-TBB resin throughout the follow-up period after sample preparation up to $24 \mathrm{~h}$, whereas significant levels of free radicals, 2-5 times greater than that on 4-META/MMA-TBB resin, were observed on RMGI up to $6 \mathrm{~h}$ (Fig. 5). The level of free radicals produced by RMGI started to decrease at $12 \mathrm{~h}$ and was similar to that of 4-META/MMA-TBB resin at $24 \mathrm{~h}$. Free radical production by calcium hydroxide was even higher than RMGI and did not decrease over $24 \mathrm{~h}$.

\section{Discussion}

These results collectively and consistently demonstrate high biocompatibility of 4-META/MMA-TBB resin with dental pulp cells, at least in comparison with a commonly used dental pulp capping calcium hydroxide-based material and a polymercontaining glassionomer cement, which is a representative restorative material of those used in current dental practice. In particular, all biological parameters were significantly better for 4-META/MMA-TBB resin than calcium hydroxide. Surviving cells, when exposed to toxic materials, may show aberrant or absent phenotypes due to functional deterioration and impaired transcription and protein translation, with compromised differentiation or induced dedifferentiation $[31,37,38]$. However, in these experiments, the cells surviving on 4-META/MMA-TBB resin were healthy enough to manifest their expected functional phenotype in vitro.

The high biocompatibility of 4-META/MMA-TBB resin was first detected as high cell viability $24 \mathrm{~h}$ after seeding, indicating that 4-META/MMA-TBB resin was the least cytotoxic of the materials tested. The percentage of viable cells was relatively low on all materials, probably due to the inclusion of dead cells suspended in the media and non-adherent to the substrates; a number of cells will always die after chemical and physical manipulation during trypsinization and standard cell culture, regardless of the type of the substrate. As expected, calcium hydroxide was most cytotoxic, with the majority of cells dying within $24 \mathrm{~h}$, presumably due to the alkaline environment. The devastating and immediate cytotoxic effect was confirmed in cell attachment assays, which revealed a significant decrease between 3 and $24 \mathrm{~h}$ of incubation on this, but not other, materials. RMGI also maintained a high percentage of viable cells, similar to that seen with 4-META/MMA-TBB resin.

The primary advantage of 4-META/MMA-TBB resin over RMGI was a greater number of attached cells during the initial stages of culture, along with a higher number of viable cells. Furthermore, the rate of cell proliferation was maintained on 4-META/MMA-TBB resin, which also contributed to higher ALP activity. These two materials were compared due to their rapid hardening properties and ability to instantly cover and protect the exposed chamber during capping. The 4-META/MMA-TBB resin is rapidly self-curing when the powder and liquid are mixed $[18,39]$, while RMGI also polymerizes rapidly via a light-curing mechanism. However, despite light curing, only $40 \%$ of RMGI was polymerized 30 min after material preparation, in contrast to $82 \%$ of 4-META/MMA-TBB resin. RMGI continues to polymerize after $30 \mathrm{~min}$ and, as a result, the remaining monomer may be released into the surrounding environment until polymerization is complete. This was confirmed by ESR, which showed continuous production of polymerization radicals from RMGI up to $24 \mathrm{~h}$ after preparation, while radical production from 4-META/ MMA-TBB resin remained low from preparation through to $24 \mathrm{~h}$. The low cytotoxicity and increased cell attachment on 4-META/ MMA-TBB resin compared to the RMGI may occur as a result of accelerated and complete polymerization of 4-META/MMA-TBB resin. Of note, the RMGI radical production subsided after $24 \mathrm{~h}$, which probably accounted for the recovery in cell proliferation and ALP production at later time points.

Restorative dentistry faces new challenges as it shifts from reparative to regenerative treatment approaches [40, 41]. One approach for regenerative pulp treatment or biologically optimized preservation is to reconstitute the normal dentin continuum at the cavity-pulp chamber interface [9]. As mentioned above, the current methods used to establish a hard border at the interface are pathogenic and may sometimes compromise clinical outcomes. The results of this study on 4-META/MMATBB resin provide the foundation to improve regenerative pulp treatment due to its high biocompatibility, moisture-insensitive polymerization behavior, and its well-established mechanical and bonding capability. 4-META/MMA-TBB resin appears to have favorable biochemical properties compared to other contemporary resin-based dental materials. Further in vivo studies are warranted.

\section{Conclusions}

4-META/MMA-TBB resin possessed a high level of biological compatibility with dental pulp cells, with high polymerization profiles and minimal production of free radicals. Together with the established favorable mechanical and bonding properties of 4-META/MMA-TBB resin and its unique, moisture-insensitive polymerization mechanism, the current results serve as a basis to further explore this material as a new pulp capping material and warrant in vivo studies.

\section{References}

[1] Ji YM, Jeon SH, Park JY, Chung JH, Choung YH, Choung PH. Dental Stem Cell Therapy with Calcium Hydroxide in Dental Pulp Capping. Tissue Eng Part A. 2010;16(6):1823-33. doi: 10.1089/ten.TEA.2009.0054.

[2] Stanley HR. Pulp capping: conserving the dental pulp--can it be done? Is it worth it? Oral Surg Oral Med Oral Pathol. 1989;68(5):628-639.

[3] Accorinte ML, Loguercio AD, Reis A, Carneiro E, Grande RH, Murata SS, et al. Response of human dental pulp capped with MTA and calcium hydroxide powder. Operative dentistry. 2008;33(5):488-495. doi: 10.2341/07-143. 
[4] Fernandes AM, Silva GA, Lopes N, Napimoga MH, Benatti BB, Alves JB. Direct capping of human pulps with a dentin bonding system and calcium hydroxide: an immunohistochemical analysis. Oral surgery, oral medicine, oral pathology, oral radiology, and endodontics. 2008;105(3):385-390. doi: 10.1016/j.tripleo.2007.08.031.

[5] Hirschfeld Z, Bab I, Tamari I, Sela J. Primary mineralization of dentin in rats after pulp capping with calcium-hydroxide. J Oral Pathol. 1982;11(6):426-433.

[6] Lu Y, Liu T, Li X, Li H, Pi G. Histologic evaluation of direct pulp capping with a self-etching adhesive and calcium hydroxide in beagles. Oral surgery, oral medicine, oral pathology, oral radiology, and endodontics. 2006;102(4):e78-84.

[7] Horsted-Bindslev P, Vilkinis V, Sidlauskas A. Direct capping of human pulps with a dentin bonding system or with calcium hydroxide cement. Oral surgery, oral medicine, oral pathology, oral radiology, and endodontics. 2003;96(5):591-600.

[8] Goldberg M, Smith AJ. Cells and Extracellular Matrices of Dentin and Pulp: a Biological Basis for Repair and Tissue Engineering. Crit Rev Oral Biol Med. 2004;15(1):13-27.

[9] Tziafas D. The future role of a molecular approach to pulpdentinal regeneration. Caries Res. 2004;38(3):314-320.

[10] Cox CF, Subay RK, Ostro E, Suzuki S, Suzuki SH. Tunnel defects in dentin bridges: their formation following direct pulp capping. Operative dentistry. 1996;21(1):4-11.

[11] Higashi T, Okamoto H. Characteristics and effects of calcified degenerative zones on the formation of hard tissue barriers in amputated canine dental pulp. J Endod. 1996;22(4):168-72.

[12] Mizuno M, Banzai Y. Calcium ion release from calcium hydroxide stimulated fibronectin gene expression in dental pulp cells and the differentiation of dental pulp cells to mineralized tissue forming cells by fibronectin. Int Endod J. 2008;41(11):933938. doi: 10.1111/j.1365-2591.2008.01420.x.

[13] Tziafas D, Panagiotakopoulos N, Komnenou A Immunolocalization of fibronectin during the early response of dog dental pulp to demineralized dentine or calcium hydroxidecontaining cement. Arch Oral Biol. 1995;40(1):23-31.

[14] Conrado CA. Remineralization of carious dentin. I: in vitro microradiographic study in human teeth capped with calcium hydroxide. Braz Dent J. 2004;15(1):59-62.

[15] Goldberg M, Six N, Decup F, Lasfargues JJ, Salih E, Tompkins $\mathrm{K}$, et al. Bioactive molecules and the future of pulp therapy. Am J Dent. 2003;16(1):66-76.

[16] Tziafas D. Mechanisms controlling secondary initiation of dentinogenesis: a review. Int Endod J. 1994;27(2):61-74.

[17] Alliot-Licht B, Jean A, Gregoire M. Comparative effect of calcium hydroxide and hydroxyapatite on the cellular activity of human pulp fibroblasts in vitro. Arch Oral Biol. 1994;39(6):481-489.

[18] Chang JC, Hurst TL, Hart DA, Estey AW. 4-META use in dentistry: a literature review. The Journal of prosthetic dentistry. 2002;87(2):216-224.

[19] Nakabayashi N, Masuhara E. Development of adhesive pit and fissure sealants using a MMA resin initiated by a tri-n-butyl borane derivative. Journal of biomedical materials research. 1978;12(2):149-165.

[20] Nakabayashi N, Kojima K, Masuhara E. The promotion of adhesion by the infiltration of monomers into tooth substrates. Journal of biomedical materials research. 1982;16(3):265-273.

[21] Aoki K, Kitasako Y, Ichinose S, Burrow MF, Ariyoshi M, Nikaido $\mathrm{T}$, et al. Ten-year observation of dentin bonding durability of 4-META/MMA-TBB resin cement--a SEM and TEM study. Dental materials journal. 2011;30(4):438-447.

[22] Tanaka Y, Sugaya T, Kawanami M. Durability of adhesion between 4-META/MMA-TBB resin and cementum. Dental materials journal. 2004;23(3):265-270.

[23] Tanaka S, Sugaya T, Kawanami M, Nodasaka Y, Yamamoto T, Noguchi $\mathrm{H}$, et al. Hybrid layer seals the cementum/4-META/ MMA-TBB resin interface. Journal of biomedical materials research Part B, Applied biomaterials. 2007;80(1):140-145.

[24] Tanaka T, Nagata K, Takeyama M, Atsuta M, Nakabayashi N, Masuhara E. 4-META opaque resin--a new resin strongly adhesive to nickel-chromium alloy. Journal of dental research. 1981;60(9):1697-1706.

[25] Nakabayashi N, Watanabe A, Gendusa NJ. Dentin adhesion of "modified" 4-META/MMA-TBB resin: function of HEMA. Dental materials : official publication of the Academy of Dental Materials. 1992;8:259-264.

[26] Tomita S, Yamamoto S, Shibukawa Y, Kaneko T, Miyakoshi S, Shimono M, et al. Application of 4-META/MMA-TBB resin for fixation of membrane to tooth in guided tissue regeneration in dog. Dental materials journal. 2010;29(6):690-696.

[27] Tsuchiya Y, Muramatsu T, Masaoka T, Hashimoto S, Shimono M. Effect of the dental adhesive, 4-META/MMA-TBB resin, on adhesion and keratinization of regenerating oral epithelium. Journal of periodontal research. 2009;44(4):496-502. doi: 10.1111/j.1600-0765.2008.01146.x.

[28] Sakai T, Morita S, Shinomiya K, Watanabe A, Nakabayashi $\mathrm{N}$, Ishihara K. In vivo evaluation of the bond strength of adhesive 4-META/MMA-TBB bone cement under weightbearing conditions. Journal of biomedical materials research. 2000;52(1):128-134.

[29] Ishihara K, Nakabayashi N. Adhesive bone cement both to bone and metals: 4-META in MMA initiated with tri-n-butyl borane. Journal of biomedical materials research. 1989;23(12):14751482.

[30] Nakamura H, Saruwatari L, Aita H, Takeuchi K, Ogawa T. Molecular and biomechanical characterization of mineralized tissue by dental pulp cells on titanium. Journal of dental research. 2005;84(6):515-520. 
[31] Kojima N, Yamada M, Paranjpe A, Tsukimura N, Kubo $\mathrm{K}$, Ogawa $\mathrm{T}$, et al. Restored viability and function of dental pulp cells on poly-methylmethacrylate (PMMA)-based dental resin supplemented with $\mathrm{N}$-acetyl cysteine (NAC). Dental materials : official publication of the Academy of Dental Materials. 2008;24(12):1686-1693. doi: 10.1016/j.dental.2008.04.008.

[32] Yamada M, Kojima N, Paranjpe A, Att W, Aita H, Ogawa T, et al. N-acetyl cysteine (NAC)-assisted detoxification of PMMA resin. Journal of dental research. 2008;87(4):372-377.

[33] Yamada M, Kojima N, Att W, Hori N, Suzuki T, Ogawa T. N-Acetyl cysteine restores viability and function of rat odontoblast-like cells impaired by polymethylmethacrylate dental resin extract. Redox Rep. 2009;14(1):13-22. doi: $10.1179 / 135100009 X 392430$.

[34] Lee C, Miura K, Liu X, Zweier JL. Biphasic regulation of leukocyte superoxide generation by nitric oxide and peroxynitrite. J Biol Chem. 2000;275(5):38965-38972.

[35] Yoshino F, Shoji H, Lee MC. Vascular effects of singlet oxygen (1O2) generated by photo-excitation on adrenergic neurotransmission in isolated rabbit mesenteric vein. Redox Rep. 2002;7(5):266-270.

[36] Lee MC, Yoshino F, Shoji H, Takahashi S, Todoki K, Shimada S, et al. Characterization by electron spin resonance spectroscopy of reactive oxygen species generated by titanium dioxide and hydrogen peroxide. Journal of dental research. 2005;84[2]:1781782 .

[37] Tsukimura N, Yamada M, Aita H, Hori N, Yoshino F, Ogawa $\mathrm{T}$, et al. N-acetyl cysteine (NAC)-mediated detoxification and functionalization of poly(methyl methacrylate) bone cement. Biomaterials. 2009;30[20]:3378-3389. doi: 10.1016/j. biomaterials.2009.02.043. Epub 2009 Mar 20.

[38] Minamikawa H, Yamada M, Iwasa F, Ueno T, Deyama $Y$, Ogawa T, et al. Amino acid derivative-mediated detoxification and functionalization of dual cure dental restorative material for dental pulp cell mineralization. Biomaterials. 2010;31[28]:72137225. doi: 10.1016/j.biomaterials.2010.06.018.

[39] Chung H, Kim M, Ko H, Yang W. Evaluation of physical and biologic properties of the mixture of mineral trioxide aggregate and 4-META/MMA-TBB resin. Oral surgery, oral medicine, oral pathology, oral radiology, and endodontics. 2011;112(5):e6-11.

[40] Goldberg M, Lacerda-Pinheiro S, Jegat N, Six N, Septier D, Priam F, et al. The impact of bioactive molecules to stimulate tooth repair and regeneration as part of restorative dentistry. Dental clinics of North America. 2006;50(2):277-298.

[41] Imazato S. Bio-active restorative materials with antibacterial effects: new dimension of innovation in restorative dentistry. Dental materials journal. 2009;28(1):11-19. 